\title{
Effects of $\gamma$-aminobutyric acid-enriched fermented sea tangle (Laminaria japonica) on brain derived neurotrophic factor-related muscle growth and lipolysis in middle aged women
}

\author{
Wook-chul Choi ${ }^{1}$, Storm N. S. Reid ${ }^{1}$, Je-kwang Ryu ${ }^{2}$,Yunsook Kim ${ }^{3}$, Young-Hong Jo ${ }^{4}$ and \\ Byeong Hwan Jeon ${ }^{1, *}$
}

${ }^{1}$ Departent of Physical Education, School of Sports and Health, Kyungsung University, Busan 48434, Korea

${ }^{2}$ Institute for Cognitive Science, College of Humanities, Seoul National University, Seoul 08826, Korea

${ }^{3}$ Marine Bio-industry Development Center, Marine Bioprocess Co., Ltd., Busan 46048, Korea

${ }^{4}$ Research and Development Team, Taekyung Food \& Processing, Seoul 07057, Korea

This study evaluated the effects of $\gamma$-aminobutyric acid (GABA)-enriched fermented sea tangle (GFST), as a functional food, on brain derived neurotrophic factor (BDNF)-related muscle growth and lipolysis, in a sarcopenic obesity highrisk group. Twenty-one middle-aged women (53-63 y) participated in this randomized, double-blind, placebo controlled study. Participants ingested either $1,000 \mathrm{mg}$ of GFST $(\mathrm{n}=10)$ or a sucrose placebo $(\mathrm{CON})(\mathrm{n}=11)$ everyday, for 8 weeks. Subjects were asked to abstain from any regular exercise. Fasting venous blood samples, body composition and muscular strength were measured before and after supplementation period. Collectively, we demonstrated that GFST significantly decreased total fat mass and triglyceride in body composition, as well as significantly increasing serum BDNF ( $p<0.001$ ), angiotensin converting enzyme $(\mathrm{p}<0.001)$, human growth hormone and insulin-like growth factor-1 levels ( $\mathrm{p}<0.05$ and $\mathrm{p}<0.05$, respectively) accompanied by increased total lean mass $(\mathrm{p}<0.01)$. Furthermore, the reported improvements in total work, knee extension and flexion at $60^{\circ} \mathrm{s}^{-1}(\mathrm{p}<0.05)$, and peak torque normalized to body weight of knee flexion at $60^{\circ} \mathrm{s}^{-1}(\mathrm{p}<0.05)$, support an ergogenic effect of GABA associated with increased growth factor levels. The use of GFST, as a functional food ingredient, to elicit anti-obesity effects and stimulate the release of muscle-related growth factors with increasing serum BDNF levels may provide a protective intervention for age-related degeneration such as sarcopenic obesity.

Key Words: brain derived neurotrophic factor; fermented sea tangle; $\gamma$-aminobutyric acid; sarcopenic obesity

Abbreviations: ACE, angiotensin converting enzyme; ALT, alanine aminotransferase; AST, aspartate aminotransferase; BDNF, brain derived neurotrophic factor; CK, creatine kinase; GABA, $\gamma$-aminobutyric acid; GFST, GABA-enriched fermented sea tangle; HDL, high-density lipoprotein; HGH, human growth hormone; IGF-1, insulin-like growth factor-1; IL, interleukin; LDL, low-density lipoprotein; mTOR, mammalian target of rapamycin; NAC, acetylcysteine; PSGL-1, Pselectin glycoprotein ligand 1; SO, sarcopenic obesity; TFM, total fat mass; TG, triglyceride; TLM, total lean mass; TNF- $\alpha$, tumor necrosis factor $\alpha$; TrK8, tyrosine kinase B

(P) $\$$ This is an Open Access article distributed under the terms of the Creative Commons Attribution Non-Commercial License (http://creativecommons.org/licenses/by-nc/3.0/) which permits unrestricted non-commercial use, distribution, and reproduction in any medium, provided the original work is properly cited.
Received March 20, 2016, Accepted June 12, 2016

* Corresponding Author

E-mail: mooaworld@ks.ac.kr

Tel: +82-51-663-4951, Fax: +82-51-663-4959 


\section{INTRODUCTION}

The progressive loss of muscle mass and volume, termed sarcopenia, often leads to functional deterioration and subsequent increases in the incidence of frailty, falls and disability, commonly coupled with high levels of adiposity (sarcopenic obesity [SO]). The multi-factorial nature of SO, mediated by numerous mechanisms, including alpha-motor neuron death, altered hormone concentrations, increased inflammation and altered nutritional status (Jones et al. 2009), necessitates comprehensive and efficacious interventions through exercise, nutrition, pharmacology, or otherwise.

Sea tangle is used frequently and widely across China, Japan, and Korea as a seasoning or dietary ingredient. Sea tangle consists of protein, amino acids, minerals, polyphenols, and insoluble cellulose rich in dietary fibre (Cha et al. 2011a). Once subjected to a highly specialized lactic acid fermentation process, using Lactobacillus brevis BJ20, glutamic acid within the sea tangle is bio-converted into $\gamma$-aminobutyric acid (GABA). GABA is a non-protein amino acid specifically functioning as an inhibitory neurotransmitter in the central nervous system. GABA has been reported to induce hypotensive effects and provide diuretic and tranquillizer effects (Inoue et al. 2003). Furthermore, supplementation of GABAenriched fermented sea tangle (GFST) has been linked to liver protection effects (Lee et al. 2010b, Cha et al. 2011b) and improvements in antioxidant levels (Lee et al. 2010a), obesity status and stress management (Okai et al. 1993, You et al. 2009). GABA supplementation has also been associated with an elevation in the levels of human growth hormone (HGH) in healthy (Cavagnini et al. 1980b) and trained men, and through this, may lead to further effects on substrate metabolism, including lipolysis and skeletal muscle protein accretion (Turner et al. 1988, De Palo et al. 2006). An angiotensin-converting enzyme (ACE) inhibiting effect has also been demonstrated following GABAenriched food ingestion, which could contribute to enhanced skeletal muscle function (Witham et al. 2008).

Loss of neuromuscular integrity is closely associated with sarcopenia (Cruz-Jentoft et al. 2010). Brain derived neurotrophic factor (BDNF) is the most prevalent neurotrophic factor in the central nervous system, and one of a number of proteins responsible for growth, differentiation and survival of neurons. Alterations in BDNF expression and signaling, linked to neurodegeneration, are typically in reference to "brain derived" rather than peripheral sources, however, BDNF is present in blood platelets (Fujimura et al. 2002), muscle cells, vascular beds, macrophages, and leucocytes (Gielen et al. 2003, Cattaneo et al. 2010), where it may be synthesized and released. Reduced serum BDNF has been soundly implicated in the pathogenesis of neurodegenerative diseases (Ventriglia et al. 2013) including dementia (Lee et al. 2009), Alzheimer's disease (Laske et al. 2007), and Parkinson's disease (Scalzo et al. 2010). Furthermore, it has been put forward that skeletal muscle-derived BDNF has a protective function on innervating motor neurons, potentiates neuromuscular transmissions and, of particular interest, stimulates protein synthesis (Oppenheim et al. 1992, Zhang and Poo 2002). Thus, on the basis of previous literature, we hypothesized that the consumption of GFST would increase the levels of blood serum biomarkers associated with muscle building and body fat status, while investigating neuromuscular survival via increased BDNF.

\section{MATERIALS AND METHODS}

\section{Participants}

Twenty-one middle-aged women (53-63 y) participated in this randomized, double-blind, placebo controlled study (Table 1). Subjects whom suffered with hypertension, chronic degenerative disease (arthritis), diabetes, obesity, and cardiovascular disease were excluded from the study. Adverse reaction to supplementation prior to the experimental period or inability to participate due to particular medication resulted in exclusion. All subjects were physically active taking part in moderate aerobic exercise (1-2 times per week). All participants completed a written informed consent to participate in this study, which was approved by Kyungsung University Ethics Committee (KSU-14-05-002).

\section{Preparation of GFST by Lactobacillus brevis BJ20 and placebo}

GFST was prepared by a previously adopted, but modified, procedure (Park et al. 2016). Sea tangle was added to

Table 1. Participant characteristics

\begin{tabular}{lcc}
\hline & Placebo $(\mathbf{n}=\mathbf{1 1})$ & Treatment $(\mathbf{n}=\mathbf{1 0})$ \\
\hline Age $(\mathrm{y})$ & 59.64 & 57.20 \\
Height $(\mathrm{cm})$ & 153.85 & 156.67 \\
Weight $(\mathrm{kg})$ & 54.45 & 56.38 \\
\hline
\end{tabular}




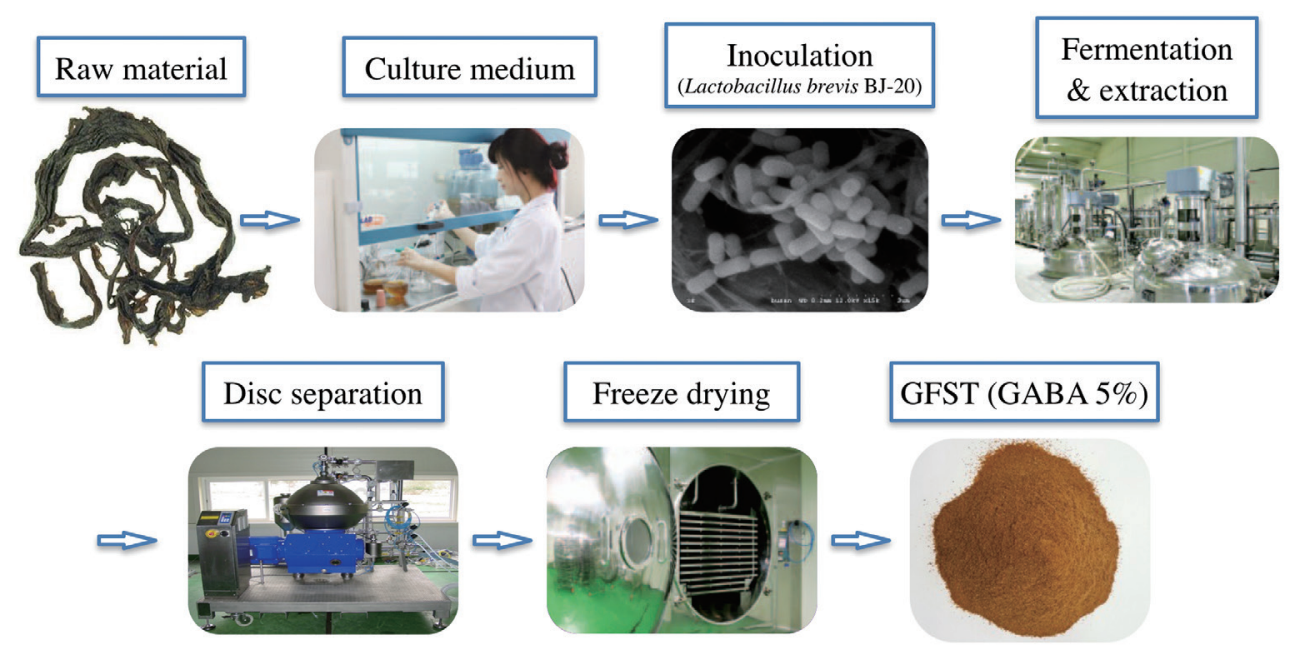

Fig. 1. Preparation process of $\gamma$-aminobutyric acid (GABA)-enriched fermented sea tangle (GFST) from raw sea tangle.

water at a ratio of $1: 15(\mathrm{w} / \mathrm{v})$ with the addition of yeast extract and glucose, based on the amount of sea tangle added to the mixture. After autoclaving at $121^{\circ} \mathrm{C}$ for 30 min, a sea tangle solution was obtained and the Lactobacillus brevis BJ20 (accession No. KCTC 11377BP) culture broth was added to the solution at a concentration of $1.2 \%(\mathrm{v} / \mathrm{v})$ (Table 2 ), which was mixed and incubated at $37^{\circ} \mathrm{C}$ for 2 days (Fig. 1). A soft capsule was made for the clinical trial by mixing $250 \mathrm{mg}$ fermented sea tangle, 61 mg lactose, $32 \mathrm{mg}$ cellulose, $5 \mathrm{mg} \mathrm{HPC,} 30 \mathrm{mg} \mathrm{SiO}$, and 7 mg magnesium stearate. A placebo was made by mixing $311 \mathrm{mg}$ lactose, $32 \mathrm{mg}$ cellulose, $5 \mathrm{mg} \mathrm{HPC}, 30 \mathrm{mg} \mathrm{\textrm {SiO } _ { 2 }}$, and $7 \mathrm{mg}$ magnesium stearate.

During the preparation process, the GABA content had been controlled to range between 40-60 mg within 1,000 mg of GFST. Based on high performance liquid chromatography analysis, it was confirmed that the mean content of GABA was $54.5 \pm 0.071 \mathrm{mg} \mathrm{g}^{-1}$ in the GFST used in this study.

\section{General protocol}

Over the experimental period, participants ingested ei- ther 1,000 mg of GFST $(n=10)$ or a sucrose placebo $(\mathrm{CON})$ ( $n=11$ ) everyday, for 8 weeks. Subjects were asked to abstain from any regular exercise. Fasting venous blood samples were taken before and after the 8 weeks period.

\section{Body composition}

Measurements of total lean mass (TLM) and total fat mass (TFM) were carried out at the Medical Centre for Health Promotion (Busan, Korea) using the DEXA (Dual Energy X-ray Absorptiometry; Discovery QDR Hologic, Bedford, MA, USA). Subjects were fitted with robes and had their measurements taken by professionally trained assistants, taking $15 \mathrm{~min}$ for the entire body.

\section{Biochemical analysis on blood}

Fasting venous blood samples were taken before and after the 8 weeks period. Collected blood samples were clotted for $30 \mathrm{~min}$ centrifugation for $15 \mathrm{~min}$ at $1,000 \times \mathrm{g}$ separated into serum and stored at $-80^{\circ} \mathrm{C}$ and analyzed by immunoassay.

Table 2. Culture broth composition

\begin{tabular}{lcccccc}
\hline & Sea tangle & Water & Yeast extract & Glucose & Seed culture & Total \\
\hline Weight (g) & 408.5 & $6,127.5$ & 10 & 5 & 76.5 & $6,627.5$ \\
Percentage (\%) & 6.2 & 92.5 & 0.2 & 0.1 & 1.2 & 100 \\
\hline
\end{tabular}

$\mathrm{Y}$-aminobutyric acid-enriched fermented sea tangle $:$ water $=1: 15(\mathrm{w} / \mathrm{v})$. 


\section{Serum substrates and inflammation factors}

Glucose substrate is an indispensable energy supplier which supports cellular function. Glucose degradation occurs in glycolysis. The hexokinase method, based on the work of Schmidt, Peterson and Young, is a recognized reference method according to the manufacturer's procedures (COBAS; Roche Diagnostics, Indianapolis, IN, USA).

Concentrations in serum of triglyceride (TG), highdensity lipoprotein (HDL) cholesterol, and low-density lipoprotein (LDL) cholesterol were enzymatically measured with commercial kits (COBAS; Roche Diagnostics).

Tumor necrosis factor $\alpha$ (TNF- $\alpha$ ) Immunoassay to measure TNF- $\alpha$ in serum, was performed by using a Quantikine HS ELISA kit provided from R\&D Systems, Inc. (Minneapolis, MN, USA). It is insensitive to the addition of recombinant forms of either of the two types of soluble receptors. It is probable that this measurement detects the total amount of TNF- $\alpha$ in serum, i.e., the total amount of free TNF- $\alpha$ plus the amount of TNF- $\alpha$ bound to soluble receptors. Optical density was determined at a wavelength of $490 \mathrm{~nm}$.

Immunoassay to measure interleukin (IL)-6 in serum was performed by using a Quantikine HS ELISA kit provided from R\&D Systems, Inc. Soluble forms of IL-6 R alpha are generated by both alternative splicing and proteolytic cleavage. In a mechanism known as trans-signaling, complexes of soluble IL-6 and IL-6 R alpha elicit responses from gp130-expressing cells that lack cell surface IL-6 R alpha.

\section{Growth-related factors}

For measuring BDNF concentrations, a commercially available kit from R\&D Systems, Inc. was used. Diluted serum was used to determine the optical density of each sample well within $30 \mathrm{~min}$ at $450 \mathrm{~nm}$.

ACE mediates the cleavage of the synthetic substrate (FAPGG; N-[3-(2-furyl)acryloyl]-L-phenylalanyl-L-glycylL-glycine) into an amino acid derivate and a dipeptide. The kinetic of this cleavage reaction is measured by recording the decrease in absorbance at $340 \mathrm{~nm}$ using a commercially available kit from BÜHLMANN Laboratories (Basel, Switzerland).

HGH concentration was determined using, a commercially available kit, Immulite 2000 from Siemens AG (Muenchen, Germany). A growth hormone releasing hormone + arginine stimulation test calibrated with both IS 80/505 and IS 98/574 (GRH Growth hormone-Recombi- nant 98/574-kit).

Insulin-like growth factor-1 (IGF-1) concentrations were measured using a solid-phase, enzyme-labeled chemiluminescent immunometric assay on the Immulite 2000 automated immunoanalyzer (Siemens AG).

\section{Strength measurements}

Isokinetic strength was measured using a Biodex machine (Biodex System 4 Pro; Biodex, Shirley, NY, USA). With subjects seated, the dynamometer was adjusted to match the rotational axis of the worked extensors and flexors. Participants were encouraged to remain seated, not moving other body parts except for the pelvis, with additional external forces applied (straps) to prevent movement of the femoral site and chest. Attachments were used to accommodate for leg length ranges of motion. Isokinetic knee flexion and extension were measured in the anatomical position, through $90^{\circ}-0^{\circ}$ and again from $0^{\circ}-90^{\circ}$ whilst being adjusted for hyperextension. Load speeds of $60^{\circ} \mathrm{s}^{-1}$ were performed on the lower limbs to assess muscle strength. All strength measurements were recorded within 7 days of starting the experimental period and 3 days of completion.

\section{Indicators of fatigue and damage on liver and muscle}

Aspartate aminotransferase (AST, or glutamate oxalacetate transaminase) and alanine aminotransferase (ALT, or glutamate pyruvate transaminase) both belong to the transaminases, which catalyze the interconversion of amino acids and $\alpha$-keto acids by transfer of amino groups. A standardized procedure provided by the manufacturer (COBAS; Roche Diagnostics) was used for AST and ALT determination. ALT determination included optimization of substrate concentrations, employment of Tris buffers, preincubation of a combined buffer and serum to allow side reactions with $\mathrm{NADH}$, substrate start and pyridoxal phosphate activation. AST measurement, included optimization of substrate concentrations, employment of Tris buffers, preincubation of a combined buffer and serum to allow side reactions with $\mathrm{NADH}$ to occur, substrate start, and optional pyridoxal phosphate activation.

Creatine kinase (CK) is rapidly inactivated by oxidation of the sulfhydryl groups in the active center. The enzyme can be reactivated by the addition of acetylcysteine (NAC). Interference by adenylate kinase is prevented by the addition of didenosine pentaphosphate and AMP. Standardized methods for the determination of CK were 
used: "reverse reaction" and activation by NAC according to the manufacturer's method (COBAS; Roche Diagnostics).

\section{Statistics}

All statistical analysis was conducted with Statistical Package for Social Sciences (SPSS Windows ver. 18.0; SPSS Inc., Chicago, IL, USA). Descriptive statistics (mean and standard deviation) were used to report on the measurements of each variable. A student paired t test and ANCOVA analysis were conducted to identify within and between group differences. Statistical significance was set at $\alpha=0.05$.

\section{RESULTS}

\section{Body composition}

Between-group differences in TLM were shown to be significantly different when comparing GFST and CON groups' pre- and post-test values $(\mathrm{p}<0.01)$ (Fig. $2 \mathrm{H}$ ). However, no within-group significance was found. TFM reduced significantly in the GFST group $(\mathrm{p}<0.05)$, but not in the CON (Fig. 2I).

\section{Lipid and inflammation}

There was no significant effect of GFST on blood glucose. We found a reduction in TG levels in the GFST group $(\mathrm{p}<0.05)$ (Fig. 2E). There were, however, no significant changes in LDL or HDL levels observed, though a notable increase was seen in the latter (Fig. 2G). There were no significant changes in IL-6 or TNF- $\alpha$ levels (Fig. 2J).

\section{BDNF and growth-related factors}

No significant within-group effect was observed in BDNF serum levels, but a between-group difference (Fig. $2 B)$ was observed $(p<0.001)$. A significant reduction was observed in the GFST $(p<0.001)$ group with respect to ACE concentrations, and between groups $(\mathrm{p}<0.01)$ (Fig. $2 \mathrm{~A}$ ). There was, however, a significant effect of supplementation on HGH levels ( $p<0.05)$, also significantly different between groups ( $<<0.001$ ) (Fig. 2C). IGF-1 increased significantly in the GFST experimental group (p $<0.05)$ (Fig. 2D).

\section{Muscle strength}

Muscle strength of the lower limb was shown to significantly improve in the GFST group for total work, knee extension and flexion at $60^{\circ} \mathrm{s}^{-1}(\mathrm{p}<0.05)$, and peak torque normalized to body weight of knee flexion at $60^{\circ} \mathrm{s}^{-1}(\mathrm{p}<$ 0.05 ) (Fig. 3A, B \& D, respectively). Peak torque normalized to body weight of knee extension also tended toward increasing but didn't reach significance.

\section{DISCUSSION}

Sea tangle is an ingredient rich in vitamins, minerals, essential fatty acids, carotenoids and bioactive compounds such as alginates and fucoidans. Supplementation of sea tangle has been associated with numerous health benefits, including anti-hyperlipidemia and anti-atherosclerosis effects (Lee et al. 2011), hypotensive (Chiu and Fung 1997) and antioxidant activities (Han et al. 2002).

Sea tangle was fermented to enrich the GABA content and evaluate the potential health benefits on SO. The prevailing research has focused on the acute changes induced by oral GABA administration with few studies on functional food intake, and to our knowledge, few reports have rigorously tested the effects of GABA rich functional foods on other biomarkers associated with neuromuscular function, body composition, blood glucose, and cholesterol status. The findings of the present study show an increase in growth factors and improvements in total body fat and lean muscle status, following GFST supplementation, via multi-mechanistic pathways (Fig. 3). Of notable interest was the increased BDNF in the experimental group along with muscle growth factors, ACE, HGH, and IGF-1.

The role of neurotrophic growth factors in neurodegenerative conditions has been the predominant focus of research surrounding nervous system health and function. However, BDNF is attracting attention for its association with neuromuscular disorders and sarcopenia. The Akt/protein kinase B activated mammalian target of rapamycin (mTOR) pathway has emerged as a key regulator of skeletal muscle hypertrophy (Lai et al. 2004), and shows a decreased activation (Kimball et al. 2004) and phosphorylation status with ageing (Haddad and Adams 2006). Muscle membrane tyrosine kinase $B$ (TrKB) receptors are thought to play a role in providing a binding site for BDNF to activate the Akt/mTOR/p70S6K signaling pathway leading to protein synthesis (Sakuma and Ya- 

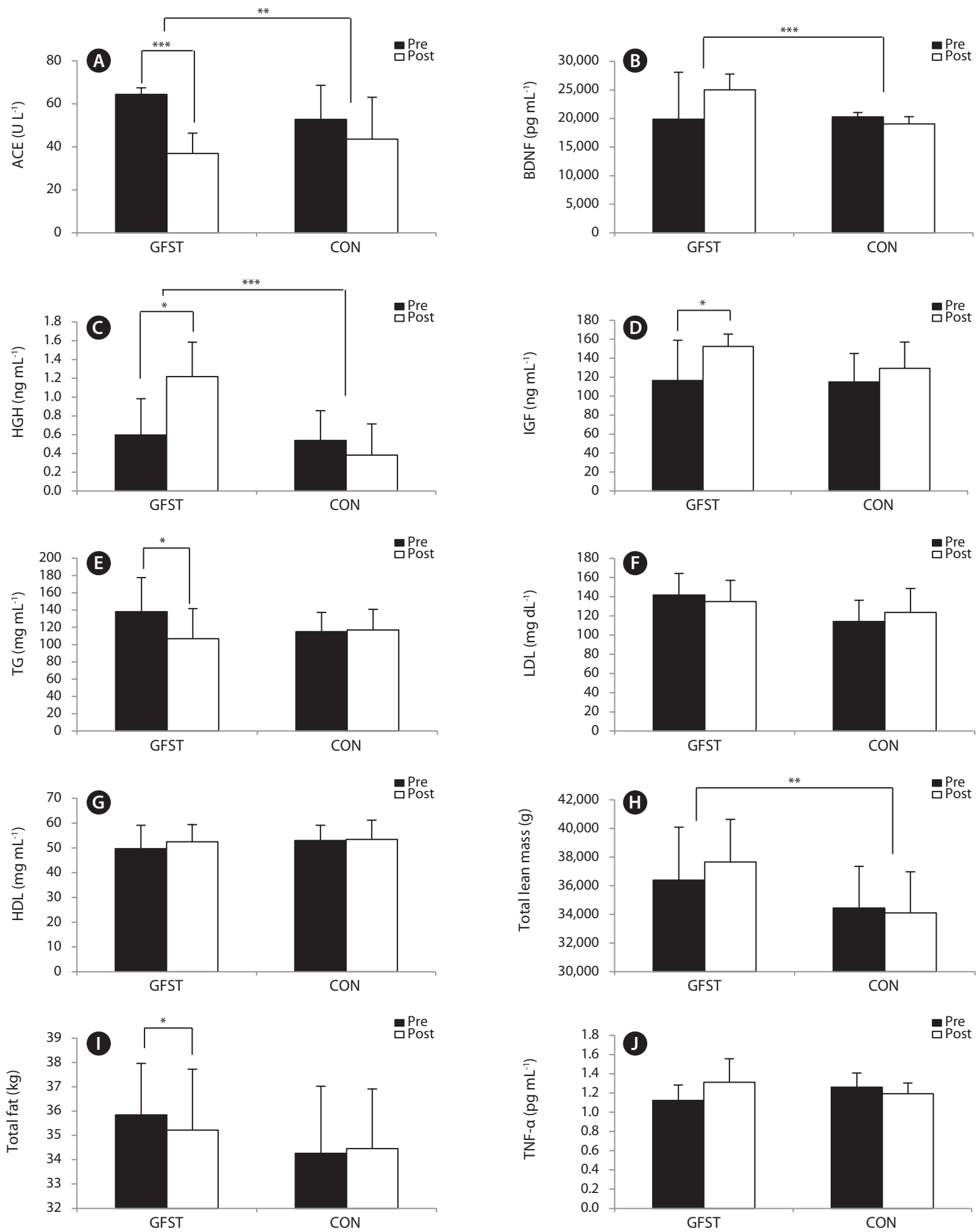

Fig. 2. Changes in blood concentrations of morphological, metabolic, hormonal, and neurotrophic factors: angiotensin converting enzyme (ACE) (A), brain derived neurotrophic factor (BDNF) (B), human growth hormone (HGH) (C), insulin-like growth hormone-1 (IGF-1) (D), triglyceride (TG) (E), low-density lipoprotein (LDL) (F), high-density lipoprotein $(H D L)(G)$, total lean mass $(H)$, total fat mass (I), and tumor necrosis factor-a (TNF-a) $(J)$. All measurements were determined before and after the experimental period. Each bar represents the mean \pm standard deviation. Student paired $t$ tests and ANCOVA analysis were conducted to identify within and between group differences, respectively. Significance values are as follows: ${ }^{*} p$ $<0.05,{ }^{* *} p<0.01,{ }^{* * *} p<0.001$. GFST, $\gamma$-aminobutyric acid-enriched fermented sea tangle; CON, placebo. 

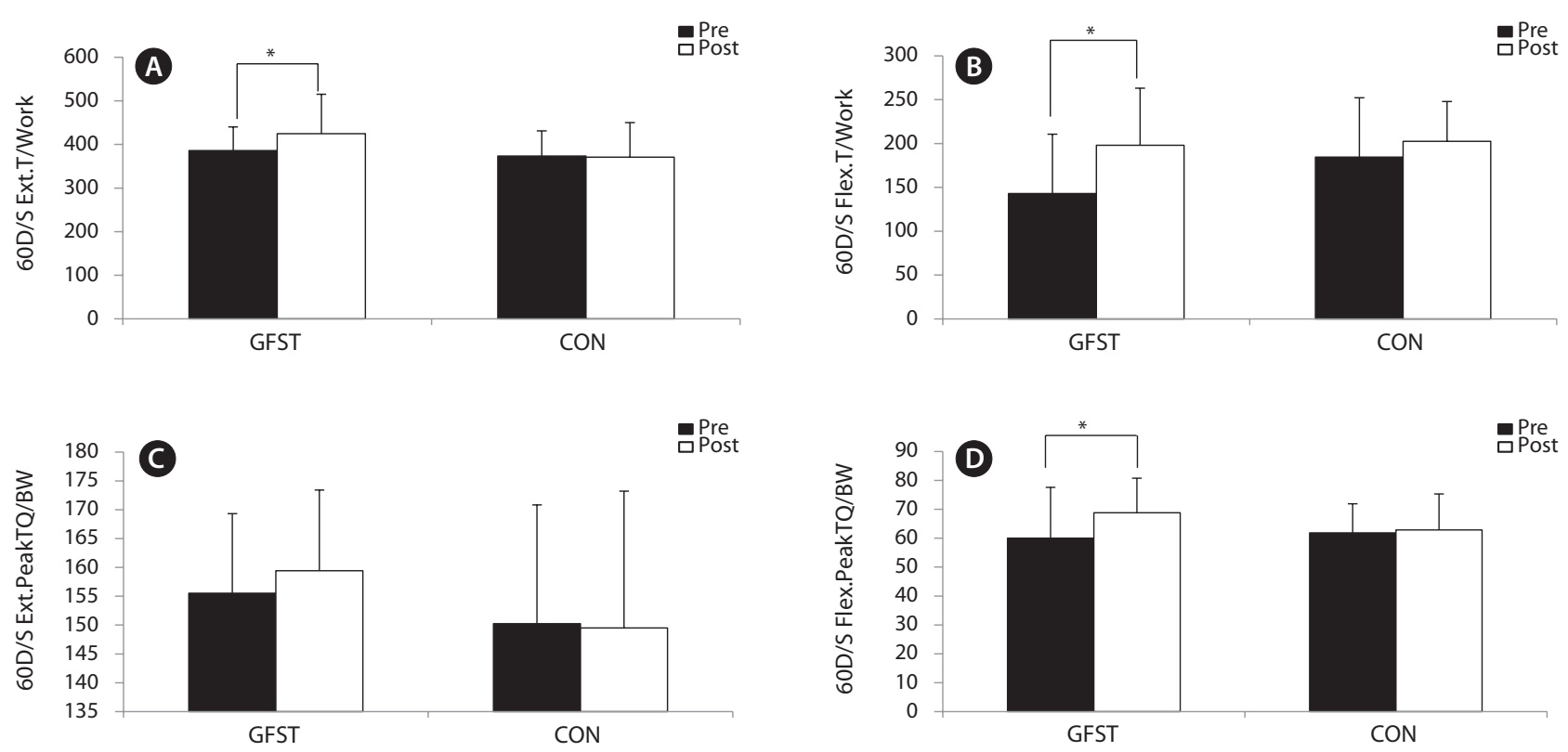

Fig. 3. Changes in muscle strength parameters. Lower limb strength measured as total work (T/Work) at $60^{\circ} \mathrm{s}^{-1}$ extension $(A)$ and flexion $(B)$, and peak torque normalized to body weight (PeakTQ/BW) at $60^{\circ} \mathrm{s}^{-1}$ extension (C) and flexion (D) pre- and post-test. Student paired t-tests and ANCOVA analysis were conducted to identify within and between group differences, respectively. Significance values are as follows: ${ }^{*} p<0.05$, ${ }^{* *} p<0.01,{ }^{* * *} p<0.001$.

maguchi 2010). In this study we demonstrated that GFST increased serum BDNF levels when baseline values were not significantly different. This indicates GFST as a viable functional food which may create an environment conducive for muscle protein synthesis. In addition, research has shown the fat oxidation AMPK-ACC signaling pathway to be enhanced as a result of BDNF induced phosphorylation in skeletal muscle (Pedersen 2011) potentially via acting in an autocrine and / or paracrine manner within skeletal muscle (Pedersen 2013). BDNF, also being low in obesity, implies a role for BDNF in the regulation of central and peripheral metabolism, potentially linked to the reduction in TFM observed in the present study. Taken together, BDNF may be identified as a myokine that influences myogenesis, muscle regeneration, and metabolism (Pedersen 2013). More studies are warranted to establish a role for GABA-related BDNF expression in SO, investigating the longitudinal effects of GABA supplementation on BDNF, and whether these translate to improvements in body composition and physical function in the ageing population.

HGH plays a key role in the maintenance and growth of skeletal muscle, and impacts the metabolism of lipids, carbohydrate, and protein in nearly all body tissue. Particular functions of HGH include the stimulation of protein anabolism (i.e., increased DNA, RNA, and protein synthesis), enhanced utilization of fats by stimulating triglyceride breakdown and oxidation of adipocytes and antagonism of insulin action (a key regulator of carbohydrate metabolism). HGH is purported to gradually decline with age at a rate of $\sim 1 \%$ per year after the age of 30 (Hermann and Berger 2001), and can be as much as 20-fold less in older than in younger adults (Ryall et al. 2008). The age-related decline in HGH, coupled with lower IGF-1 levels, the key mediator of HGH action, have also been associated with sarcopenia and detrimental changes in body composition (Ferrucci et al. 2002). The results of the current study demonstrated a significant increase in HGH as a result of GFST supplementation. Some of the early GABA research on oral supplementation showed significant elevation in plasma HGH levels in healthy men (Cavagnini et al. 1980a). It is important to note that the majority of research investigates the acute changes in HGH levels (Cavagnini et al. 1980a) whereas, the current study presents a case for long term increases in resting HGH with continual supplementation of GABA; a within and between groups effect of GFST was observed after 8 weeks (Fig. 2C). A HGH induced generation of IGF1 , in accordance with the somatomedin hypothesis (Le Roith et al. 2001), may be responsible for the significant 


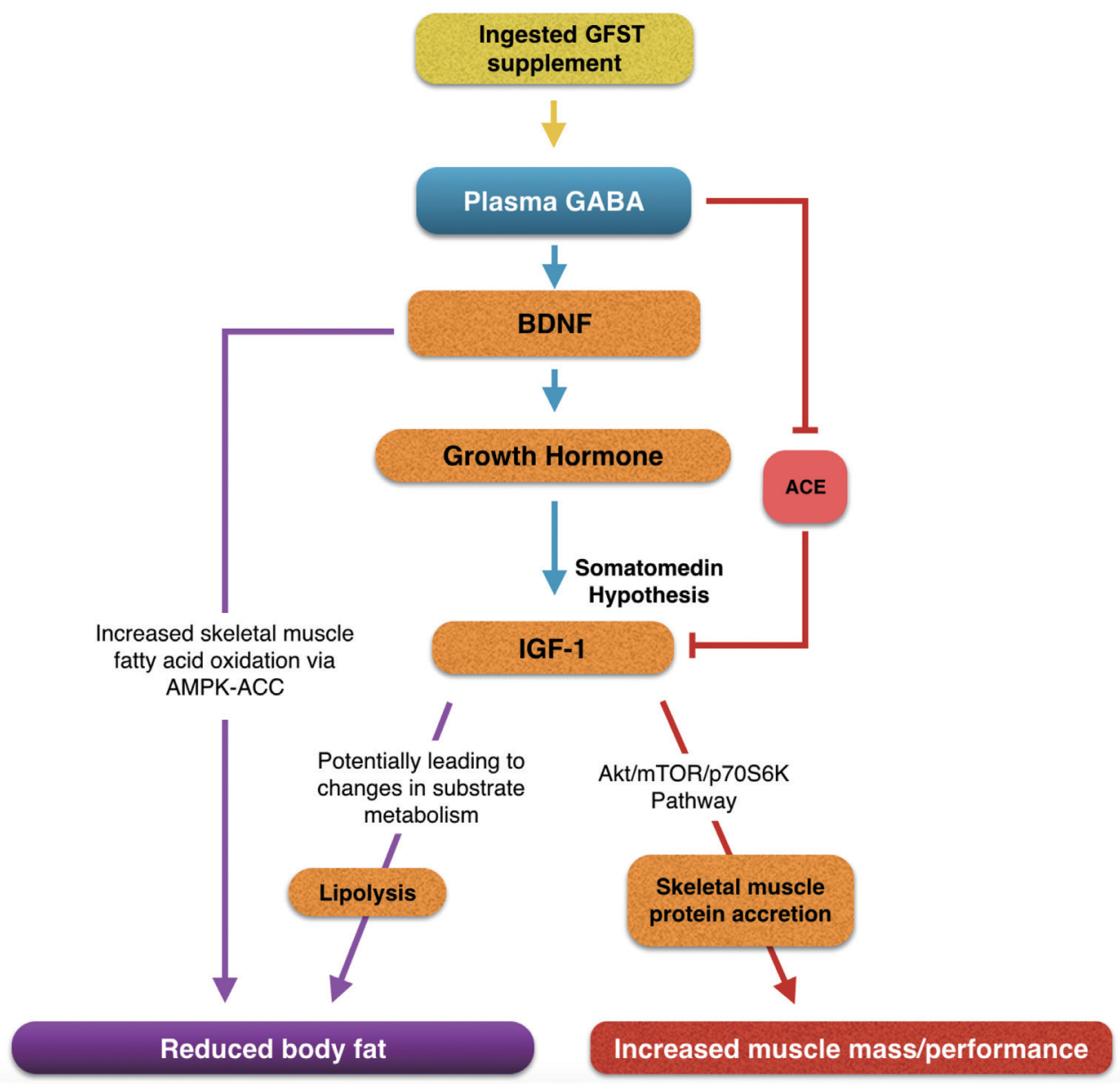

Fig. 4. Mechanism map of potential pathways $\gamma$-aminobutyric acid (GABA) may affect muscle growth and body fat reduction changes. ACE, angiotensin converting enzyme; BDNF, brain derived neurotrophic factor; GFST, GABA-enriched fermented sea tangle; IGF-1, insulin-like growth factor-1; mTOR, mammalian target of rapamycin.

increase in IGF-1 (Fig. 2D) (Laron 1996), and thus, an ensuing anabolic or lipolytic response (De Palo et al. 2006) demonstrated by an increase in TLM (Fig. 2H) and decrease in TFM (Fig. 2I) following GFST supplementation. Furthermore, inferring a stimulatory effect of GABA on HGH levels, the tendency toward a reduction in LDL and increase in HDL concentrations shown in the GFST group (Fig. 1G), help support the notion that following HGH release IGF-1 has a modulating role on insulin sensitivity (Moses et al. 1996) and HDL levels further downstream (Succurro et al. 2010). The relative contributions of these IGF-1 pathways require further investigation, due to the ubiquitous nature of IGF-1, IGF-1, and HGH independent growth stimulating effects (Laron 2001), and / or the possibility of GABA directly stimulating hypothalamic responses (i.e., ghrelin, growth hormone-releasing hormone, and somatostatin) (Powers 2012).
Our results may give an important contribution to the question of whether ACE inhibitor use can aid in sarcopenia treatment. The renin-angiotensin system is known to be activated in many catabolic conditions, in which ACE is responsible for converting angiotensin I to angiotensin II, in a process that regulates blood pressure and the body's fluid and sodium balance. Angiotensin II infusion resulted in cachexia and decreased circulating IGF-1. The weight loss was associated with skeletal muscle catabolism, in the presence of unchanged fat tissue, possibly via its inhibitory effect on the autocrine IGF-1 system (Brink et al. 2001), and more specifically, via the Akt/mTOR/p706SK pathway (Song et al. 2005). Thus, the inhibitory effect of GABA on ACE demonstrated in the present study, and previously evidenced in the literature (Lin and Omori 2002), points toward a major mechanistic pathway to target in catabolic conditions such as sarco- 
penia. The extent to which ACE inhibition contributed to the increase in IGF-1 or TLM, in the current study, is unknown, although it may act synergistically with other mechanisms (Fig. 4). Future investigation ought to be carried out on the effects of ACE inhibitors on musclespecific IGF-I expression in healthy, ageing subjects. Of particular interest to the application of functional foods as lipid status improving agents, was the reduction in TFM $(\mathrm{p}<0.05)$, increased HDL concentration and significant decrease in TG levels $(\mathrm{p}<0.05)$ following GFST supplementation. Brown seaweeds are known to be rich in polysaccharides such as fucoidan, laminarin, and alginate. Fucoidan of brown seaweed has been implicated in the reduction of blood lipids (Li et al. 2008), decrease in total cholesterol, triglycerides, and LDL concentration, and increase in HDL concentration (Li et al. 2001). In addition, reduced cholesterol and triglycerides has been reported in patients with hyperlipidaemia following fucoidan ingestion (Wang and Bi 1994). Up-regulation of lipid metabolic enzymes (Huang et al. 2010) is one proposed mechanism by which fucoidan may help to improve lipid profiles. Obesity can be expressed, partly, as a state of chronic low grade inflammation in adipose tissue, caused by adipocyte hypertrophy and hyperplasia, marked by an increase in macrophage content and activity in the adipose tissue, inducing a release of cytokines and pro-inflammatory signals. Leukocyte trafficking into adipose tissue is mediated by increased endothelial expression of P-selectins and E-selectins (Nishimura et al. 2008), and the regulatory role of P-selectin glycoprotein ligand 1 (PSGL-1) on the adhesive properties of the endothelium and leukocyte. PSGL-1 deficiency was shown to have protective effects against visceral fat inflammation in mice, by reducing IL-1 receptor-mediated adhesive properties of the endothelium (Russo et al. 2010). Furthermore, antibody blockade of P- and E-selectin reduced leukocyte rolling and firm attachment in obese visceral adipose tissue (Nishimura et al. 2008). Fucoidan acts as a "selectin blocker" (Kylin 1913) and therefore may reduce selectin-dependant leukocyte rolling on endothelial cells, subsequently leading to a reduced inflammatory state. It is known that leukocyte and neutrophils correlate positively with increased visceral fat in obese individuals (Ryder et al. 2014), thus targeting the adhesive properties of endothelial cells may prove an efficacious treatment for inflammatory disease states.

Another property of sea tangle is alginate, a dietary fibre extracted from the cell walls of brown seaweed. Studies have reported a reduction in body fat percentage
(Georg et al. 2012), acute modulations in human-appetite sensation (Paxman et al. 2008) and decreased gastric emptying rate attributed to alginate ingestion. Inhibition of digestive enzymes in vitro (namely, pancreatic lipase) (Wilcox et al. 2014) and altered intestinal content viscosity are proposed key factors mediating the uptake of triacylglycerol and promoting the control of energy intake (Kristensen and Jensen 2011), respectively. These effects are still inconclusive (Odunsi et al. 2010) and warrant further investigation. Special attention should be given to the effectiveness of alginates extracted from different types of seaweed, the dose-dependency of alginate usage (the more alginate the less enzyme activity) and the palatability of potential supplements.

To our knowledge, no previous studies have investigated the effects of GABA-enriched functional foods on performance outcomes, particularly strength. Our findings of significantly improved isokinetic strength (Fig. 3A, B \& D) in the GFST group help support the stance that functional foods, such as GFST, can significantly enhance growth factor levels, such as HGH and IGF-1, resulting in functional improvements in performance. The inclusion of functional foods as part of a holistic intervention seems an efficacious, noninvasive and practical approach in tackling SO and improving the ability to carry out active daily living tasks with age. It can also be added that no adverse effects to the liver were reported following GFST supplementation (Appendix 1). In this study, we demonstrated that GFST significantly decreased TFM and TG, as well as significantly increasing serum BDNF, ACE, HGH, and IGF-1 levels.

In conclusion, the use of functional foods, particularly GFST, to increase the levels of circulating GABA may stimulate the release of muscle-related growth factors including serum BDNF and / or affect substrate metabolism, providing a safe, protective intervention for age-related conditions such as SO. However, further studies concerning GFST as a functional food and its potential use in conditions such as SO should be addressed.

\section{ACKNOWLEDGEMENTS}

This work was supported by the Industrial Strategic Technology Development Program (10048025, development of health functional food of the brain for the elderly for the entry into the global market) funded by the Ministry of Trade, Industry \& Energy (MI, Korea). 


\section{REFERENCES}

Brink, M., Price, S. R., Chrast, J., Bailey, J. L., Anwar, A., Mitch, W. E. \& Delafontaine, P. 2001. Angiotensin II induces skeletal muscle wasting through enhanced protein degradation and down-regulates autocrine insulin-like growth factor I. Endocrinology 142:1489-1496.

Cattaneo, A., Bocchio-Chiavetto, L., Zanardini, R., Milanesi, E., Placentino, A. \& Gennarelli, M. 2010. Reduced peripheral brain-derived neurotrophic factor mRNA levels are normalized by antidepressant treatment. Int. J. Neuropsychopharmacol. 13:103-108.

Cavagnini, F., Benetti, G., Invitti, C., Ramella, G., Pinto, M., Lazza, M., Dubini, A., Marelli, A. \& Müller, E. E. $1980 a$. Effect of gamma-aminobutyric acid on growth hormone and prolactin secretion in man: influence of pimozide and domperidone. J. Clin. Endocrinol. Metab. 51:789792.

Cavagnini, F., Invitti, C., Pinto, M., Maraschini, C., Di Landro, A., Dubini, A. \& Marelli, A. 1980b. Effect of acute and repeated administration of gamma aminobutyric acid (GABA) on growth hormone and prolactin secretion in man. Acta Endocrinol. (Copenh.) 93:149-154.

Cha, J. -Y., Jeong, J. -J., Yang, H. -J., Lee, B. -J. \& Cho, Y. -S. $2011 a$. Effect of fermented sea tangle on the alcohol dehydrogenase and acetaldehyde dehydrogenase in Saccharomyces cerevisiae. J. Microbiol. Biotechnol. 21:791795.

Cha, J. -Y., Lee, B. -J., Je, J. -Y., Kang, Y. -M., Kim, Y. -M. \& Cho, Y. -S. 2011b. GABA-enriched fermented Laminaria japonica protects against alcoholic hepatotoxicity in Sprague-Dawley rats. Fish. Aquat. Sci. 14:79-88.

Chiu, K. W. \& Fung, A. Y. L. 1997. The cardiovascular effects of green beans (Phaseolus aureus), common rue (Ruta graveolens), and kelp (Laminaria japonica) in rats. Gen. Pharmacol. 29:859-862.

Cruz-Jentoft, A. J., Baeyens, J. P., Bauer, J. M., Boirie, Y., Cederholm, T., Landi, F., Martin, F. C., Michel, J. -P., Rolland, Y., Schneider, S. M., Topinková, E., Vandewoude, M. \& Zamboni, M. 2010. Sarcopenia: European consensus on definition and diagnosis: Report of the European Working Group on Sarcopenia in Older People. Age Ageing 39:412-423.

De Palo, E. F., Gatti, R., Antonelli, G. \& Spinella, P. 2006. Growth hormone isoforms, segments/fragments: does a link exist with multifunctionality? Clin. Chim. Acta 364:77-81.

Ferrucci, L., Penninx, B. W. J. H., Volpato, S., Harris, T. B., Bandeen-Roche, K., Balfour, J., Leveille, S. G., Fried, L. P. \& Md, J. M. G. 2002. Change in muscle strength explains accelerated decline of physical function in older women with high interleukin-6 serum levels. J. Am. Geriatr. Soc. 50:1947-1954.

Fujimura, H., Altar, C. A., Chen, R., Nakamura, T., Nakahashi, T., Kambayashi, J., Sun, B. \& Tandon, N. N. 2002. Brainderived neurotrophic factor is stored in human platelets and released by agonist stimulation. Thromb. Haemost. 87:728-734.

Georg, M. G., Kristensen, M., Belza, A., Knudsen, J. C. \& Astrup, A. 2012. Acute effect of alginate-based preload on satiety feelings, energy intake, and gastric emptying rate in healthy subjects. Obesity 20:1851-1858.

Gielen, A., Khademi, M., Muhallab, S., Olsson, T. \& Piehl, F. 2003. Increased brain-derived neurotrophic factor expression in white blood cells of relapsing-remitting multiple sclerosis patients. Scand. J. Immunol. 57:493-497.

Haddad, F. \& Adams, G. R. 2006. Aging-sensitive cellular and molecular mechanisms associated with skeletal muscle hypertrophy. J. Appl. Physiol. 100:1188-1203.

Han, J., Kang, S., Choue, R., Kim, H., Leem, K., Chung, S., Kim, C. \& Chung, J. 2002. Free radical scavenging effect of Diospyros kaki, Laminaria japonica and Undaria pinnatifida. Fitoterapia 73:710-712.

Hermann, M. \& Berger, P. 2001. Hormonal changes in aging men: a therapeutic indication? Exp. Gerontol. 36:10751082.

Huang, L., Wen, K., Gao, X. \& Liu, Y. 2010. Hypolipidemic effect of fucoidan from Laminaria japonica in hyperlipidemic rats. Pharm. Biol. 48:422-426.

Inoue, K., Shirai, T., Ochiai, H., Kasao, M., Hayakawa, K., Kimura, M. \& Sansawa, H. 2003. Blood-pressurelowering effect of a novel fermented milk containing $\gamma$-aminobutyric acid (GABA) in mild hypertensives. Eur. J. Clin. Nutr. 57:490-495.

Jones, T. E., Stephenson, K. W., King, J. G., Knight, K. R., Marshall, T. L. \& Scott, W. B. 2009. Sarcopenia: mechanisms and treatments. J. Geriatr. Phys. Ther. 3:39-45.

Kimball, S. R., O’Malley, J. P., Anthony, J. C., Crozier, S. J. \& Jefferson, L. S. 2004. Assessment of biomarkers of protein anabolism in skeletal muscle during the life span of the rat: sarcopenia despite elevated protein synthesis. Am. J. Physiol. Endocrinol. Metab. 287:E772-E780.

Kristensen, M. \& Jensen, M. G. 2011. Dietary fibres in the regulation of appetite and food intake: importance of viscosity. Appetite 56:65-70.

Kylin, H. 1913. Zur Biochemie der Meeresalgen. Hoppe-Seyler's Z. Physiol. Chem. 83:171-197.

Lai, K. -M. V., Gonzalez, M., Poueymirou, W. T., Kline, W. O., Na, E., Zlotchenko, E., Stitt, T. N., Economides, A. N., Yancopoulos, G. D. \& Glass, D. J. 2004. Conditional acti- 
vation of Akt in adult skeletal muscle induces rapid hypertrophy. Mol. Cell Biol. 24:9295-9304.

Laron, Z. 1996. The somatostatin-GHRH-GH-IGF-I axis. In Merimee, T. \& Laron, Z. (Eds.) Growth Hormone, IGF-I and Growth: New Views of Old Concepts: Modern Endocrinology and Diabetes. Freund Publishing House Ltd., London-Tel Aviv, pp. 5-10.

Laron, Z. 2001. Insulin-like growth factor 1 (IGF-1): a growth hormone. Mol. Pathol. 54:311-316.

Laske, C., Stransky, E., Leyhe, T., Eschweiler, G. W., Maetzler, W., Wittorf, A., Soekadar, S., Richartz, E., Koehler, N., Bartels, M., Buchkremer, G. \& Schott, K. 2007. BDNF serum and CSF concentrations in Alzheimer's disease, normal pressure hydrocephalus and healthy controls. J. Psychiatr. Res. 41:387-394.

Lee, B. -J., Kim, J. -S., Kang, Y. M., Lim, J. -H., Kim, Y. -M., Lee, M. -S., Jeong, M. -H., Ahn, C. -B. \& Je, J. -Y. 2010a. Antioxidant activity and $\gamma$-aminobutyric acid (GABA) content in sea tangle fermented by Lactobacillus brevis BJ20 isolated from traditional fermented foods. Food Chem. 122:271-276.

Lee, B. -J., Senevirathne, M., Kim, J. -S., Kim, Y. -M., Lee, M. -S., Jeong, M. -H., Kang, Y. M., Kim, J. I., Nam, B. -H., Ahn, C. -B. \& Je, J. -Y. 2010b. Protective effect of fermented sea tangle against ethanol and carbon tetrachlorideinduced hepatic damage in Sprague-Dawley rats. Food Chem. Toxicol. 48:1123-1128.

Lee, J. G., Shin, B. S., You, Y. S., Kim, J. E., Yoon, S. W., Jeon, D. W., Baek, J. H., Park, S. W. \& Kim, Y. H. 2009. Decreased serum brain-derived neurotrophic factor levels in elderly Korean with dementia. Psychiatr. Invest. 6:299-305.

Lee, S. -J., Kim, C. -W., Jang, H., -J., Cho, S. Y., \& Choi, J. -W. 2011. Anti-hyperlipidemia and anti-arteriosclerosis effects of Laminaria japonica in Sprague-Dawley rats. Fish. Aquat. Sci. 14:235-241.

Le Roith, D., Bondy, C., Yakar, S., Liu, J. L. \& Butler, A. 2001. The somatomedin hypothesis: 2001. Endocr. Rev. 22:5374.

Li, B., Lu, F., Wei, X. \& Zhao, R. 2008. Fucoidan: structure and bioactivity. Molecules 13:1671-1695.

Li, D. Y., Xu, Z., Huang, L. M., Wang, H. B. \& Zhang, S. H. 2001. Effect of fucoidan of L. japonica on rats with hyperlipidaemia. Food Sci. 22:92-95.

Lin, Z. \& Omori, M. 2002. Effects of gabaron tea components on angiotension I-converting enzyme activity in rat. J. Tea Sci. 22:43-46.

Moses, A. C., Young, S. C. J., Morrow, L. A., O’Brien, M. \& Clemmons, D. R. 1996. Recombinant human insulinlike growth factor I increases insulin sensitivity and improves glycemic control in type II diabetes. Diabetes
45:91-100.

Nishimura, R., Baker, J., Beilhack, A., Zeiser, R., Olson, J. A., Sega, E. I., Karimi, M. \& Negrin, R. S. 2008. In vivo trafficking and survival of cytokine-induced killer cells resulting in minimal GVHD with retention of antitumor activity. Blood 112:2563-2574.

Odunsi, S. T., Vázquez-Roque, M. I., Camilleri, M., Papathanasopoulos, A., Clark, M. M., Wodrich, L., Lempke, M., McKinzie, S., Ryks, M., Burton, D. \& Zinsmeister, A. R. 2010. Effect of alginate on satiation, appetite, gastric function, and selected gut satiety hormones in overweight and obesity. Obesity 18:1579-1584.

Okai, Y., Higashi-Okai, K. \& Nakamura, S. 1993. Identification of heterogenous antimutagenic activities in the extract of edible brown seaweeds, Laminaria japonica (Makonbu) and Undaria pinnatifida (Wakame) by the umu gene expression system in Salmonella typhimurium (TA1535/pSK1002). Mutat. Res. 303:63-70.

Oppenheim, R. W., Yin, Q. W., Prevette, D. \& Yan, Q. 1992. Brain-derived neurotrophic factor rescues developing avian motoneurons from cell death. Nature 360:755-757.

Park, H. -J., Lee, M. -S., Shim, H. S., Lee, G. -R., Chung, S. Y., Kang, Y. M., Lee, B. -J., Seo, Y. B., Kim, K. S. \& Shim, I. 2016. Fermented Saccharina japonica (Phaeophyta) improves neuritogenic activity and TMT-induced cognitive deficits in rats. Algae 31:73-84.

Paxman, J. R., Richardson, J. C., Dettmar, P. W. \& Corfe, B. M. 2008. Daily ingestion of alginate reduces energy intake in free-living subjects. Appetite 51:713-719.

Pedersen, B. K. 2011. Exercise-induced myokines and their role in chronic diseases. Brain Behav. Immun. 25:811816.

Pedersen, B. K. 2013. Muscle as a secretory organ. Compr. Physiol. 3:1337-1362.

Powers, M. 2012. GABA supplementation and growth hormone response. Acute Topics in Sports Nutrition. Med. Sport Sci. 59:36-46.

Russo, H. M., Wickenheiser, K. J., Luo, W., Öhman, M. K., Franchi, L., Wright, A. P., Bodary, P. F., Núñez, G. \& Eitzman, D. T. 2010. P-selectin glycoprotein ligand-1 regulates adhesive properties of the endothelium and leukocyte trafficking into adipose tissue. Circ. Res. 107:388-397.

Ryall, J. G., Schertzer, J. D. \& Lynch, G. S. 2008. Cellular and molecular mechanisms underlying age-related skeletal muscle wasting and weakness. Biogerontology 9:213228.

Ryder, E., Diez-Ewald, M., Mosquera, J., Fernández, E., Pedreañez, A., Vargas, R., Peña, C. \& Fernández, N. 2014. Association of obesity with leukocyte count in obese individuals without metabolic syndrome. Diabetes Metab. 
Syndr. 8:197-204.

Sakuma, K. \& Yamaguchi, A. 2010. Molecular mechanisms in aging and current strategies to counteract sarcopenia. Curr. Aging Sci. 3:90-101.

Scalzo, P., Kümmer, A., Bretas, T. L., Cardoso, F. \& Teixeira, A. L. 2010. Serum levels of brain-derived neurotrophic factor correlate with motor impairment in Parkinson's disease. J. Neurol. 257:540-545.

Song, Y. -H., Li, Y., Du, J., Mitch, W. E., Rosenthal, N. \& Delafontaine, P. 2005. Muscle-specific expression of IGF-1 blocks angiotensin II-induced skeletal muscle wasting. J. Clin. Invest. 115:451-458.

Succurro, E., Arturi, F., Grembiale, A., Iorio, F., Laino, I., Andreozzi, F., Sciacqua, A., Hribal, M. L., Perticone, F. \& Sesti, G. 2010. Positive association between plasma IGF1 and high-density lipoprotein cholesterol levels in adult nondiabetic subjects. Eur. J. Endocrinol. 163:75-80.

Turner, J. D., Rotwein, P., Novakofski, J. \& Bechtel, P. J. 1988. Induction of mRNA for IGF-I and -II during growth hormone-stimulated muscle hypertrophy. Am. J. Physiol. 255:E513-E517.
Ventriglia, M., Zanardini, R., Bonomini, C., Zanetti, O., Volpe, D., Pasqualetti, P., Gennarelli, M. \& Bocchio-Chiavetto, L. 2013. Serum brain-derived neurotrophic factor levels in different neurological diseases. BioMed. Res. Int. 2013:901082.

Wang, S. Z. \& Bi, A. F. 1994. Clinic observation of fucoidan on patients with hyperlipidaemia. Med. J. Qilu. 16:173-174.

Wilcox, M. D., Brownlee, I. A., Richardson, J. C., Dettmar, P. W. \& Pearson, J. P. 2014. The modulation of pancreatic lipase activity by alginates. Food Chem. 146:479-484.

Witham, M. D., Sumukadas, D. \& McMurdo, M. E. 2008. ACE inhibitors for sarcopenia: as good as exercise training? Age Ageing 37:363-365.

You, J. S., Sung, M. J. \& Chang, K. J. 2009. Evaluation of 8-week body weight control program including sea tangle (Laminaria japonica) supplementation in Korean female college students. Nutr. Res. Pract. 3:307-314.

Zhang, X. H. \& Poo, M. M. 2002. Localized synaptic potentiation by BDNF requires local protein synthesis in the developing axon. Neuron 36:675-688. 
Appendix 1. Change of blood biomarkers and body composition parameters

\begin{tabular}{|c|c|c|c|c|c|}
\hline Variable & Group & Pre & Post & t & F \\
\hline ACE & $\begin{array}{l}\text { GFST } \\
\text { CON }\end{array}$ & $\begin{array}{l}64.90 \pm 2.73 \\
52.34 \pm 19.30\end{array}$ & $\begin{array}{l}36.95 \pm 9.40 \\
43.61 \pm 19.45\end{array}$ & $\begin{array}{l}9.173^{* * *} \\
2.322\end{array}$ & $10.225^{* *}$ \\
\hline BDNF & $\begin{array}{l}\text { GFST } \\
\text { CON }\end{array}$ & $\begin{array}{l}20,793.73 \pm 3,771.82 \\
20,260.97 \pm 7,158.04\end{array}$ & $\begin{array}{l}25,024.65 \pm 2,760.31 \\
20,187.67 \pm 2,927.66\end{array}$ & $\begin{array}{r}-2.526 \\
2.373\end{array}$ & $23.262^{* * *}$ \\
\hline IL-6 & $\begin{array}{l}\text { GFST } \\
\text { CON }\end{array}$ & $\begin{array}{l}1.07 \pm 0.65 \\
1.16 \pm 0.60\end{array}$ & $\begin{array}{l}1.38 \pm 0.81 \\
1.16 \pm 0.59\end{array}$ & $\begin{array}{r}-1.721 \\
0.005\end{array}$ & 1.120 \\
\hline TNF- $a$ & $\begin{array}{l}\text { GFST } \\
\text { CON }\end{array}$ & $\begin{array}{l}1.12 \pm 0.16 \\
1.16 \pm 0.26\end{array}$ & $\begin{array}{l}1.31 \pm 0.24 \\
1.15 \pm 0.14\end{array}$ & $\begin{array}{r}-2.070 \\
0.119\end{array}$ & 3.678 \\
\hline $\mathrm{HGH}$ & $\begin{array}{l}\text { GFST } \\
\text { CON }\end{array}$ & $\begin{array}{l}0.59 \pm 0.38 \\
0.58 \pm 0.37\end{array}$ & $\begin{array}{l}1.21 \pm 0.36 \\
0.38 \pm 0.33\end{array}$ & $\begin{array}{c}-3.217^{*} \\
0.918\end{array}$ & $18.743^{* * *}$ \\
\hline IGF & $\begin{array}{l}\text { GFST } \\
\text { CON }\end{array}$ & $\begin{array}{l}116.45 \pm 42.50 \\
114.72 \pm 19.13\end{array}$ & $\begin{array}{l}152.47 \pm 30.00 \\
130.42 \pm 31.20\end{array}$ & $\begin{array}{l}-2.454^{*} \\
-2.364\end{array}$ & 2.176 \\
\hline AST & $\begin{array}{l}\text { GFST } \\
\text { CON }\end{array}$ & $\begin{array}{l}24.80 \pm 5.84 \\
22.63 \pm 3.50\end{array}$ & $\begin{array}{l}25.40 \pm 4.50 \\
23.63 \pm 2.37\end{array}$ & $\begin{array}{l}-0.580 \\
-1.158\end{array}$ & 0.253 \\
\hline ALT & $\begin{array}{l}\text { GFST } \\
\text { CON }\end{array}$ & $\begin{array}{l}19.40 \pm 11.21 \\
16.27 \pm 8.84\end{array}$ & $\begin{array}{l}16.60 \pm 7.42 \\
13.00 \pm 3.89\end{array}$ & $\begin{array}{l}1.057 \\
1.514\end{array}$ & 1.419 \\
\hline CK & $\begin{array}{l}\text { GFST } \\
\text { CON }\end{array}$ & $\begin{array}{l}74.71 \pm 14.64 \\
95.54 \pm 27.90\end{array}$ & $\begin{array}{l}72.00 \pm 15.25 \\
98.81 \pm 32.00\end{array}$ & $\begin{array}{r}0.699 \\
-0.451\end{array}$ & 0.960 \\
\hline Glucose & $\begin{array}{l}\text { GFST } \\
\text { CON }\end{array}$ & $\begin{array}{l}97.50 \pm 7.69 \\
88.72 \pm 32.00\end{array}$ & $\begin{array}{l}97.10 \pm 12.03 \\
92.63 \pm 5.97\end{array}$ & $\begin{array}{r}0.113 \\
-1.467\end{array}$ & 0.042 \\
\hline TG & $\begin{array}{l}\text { GFST } \\
\text { CON }\end{array}$ & $\begin{array}{l}138.14 \pm 39.38 \\
115.00 \pm 22.41\end{array}$ & $\begin{array}{l}106.85 \pm 34.88 \\
117.00 \pm 23.86\end{array}$ & $\begin{array}{l}3.025^{*} \\
-0.254\end{array}$ & 3.752 \\
\hline LDL & $\begin{array}{l}\text { GFST } \\
\text { CON }\end{array}$ & $\begin{array}{l}141.75 \pm 22.57 \\
110.09 \pm 24.95\end{array}$ & $\begin{array}{l}134.87 \pm 23.41 \\
119.27 \pm 17.67\end{array}$ & $\begin{array}{r}1.099 \\
-2.018\end{array}$ & 1.578 \\
\hline HDL & $\begin{array}{l}\text { GFST } \\
\text { CON }\end{array}$ & $\begin{array}{l}49.71 \pm 9.41 \\
53.44 \pm 7.74\end{array}$ & $\begin{array}{l}52.42 \pm 6.97 \\
53.88 \pm 9.42\end{array}$ & $\begin{array}{l}-1.546 \\
-0.144\end{array}$ & 0.041 \\
\hline Total lean mass & $\begin{array}{l}\text { GFST } \\
\text { CON }\end{array}$ & $\begin{array}{l}36,396.32 \pm 3,696.55 \\
34,436.18 \pm 2,912.06\end{array}$ & $\begin{array}{l}37,410.76 \pm 2,985.98 \\
34,105.06 \pm 2,865.53\end{array}$ & $\begin{array}{r}-2.257 \\
1.016\end{array}$ & $10.360^{* *}$ \\
\hline Total fat & $\begin{array}{l}\text { GFST } \\
\text { CON }\end{array}$ & $\begin{array}{l}35.33 \pm 2.42 \\
34.26 \pm 2.75\end{array}$ & $\begin{array}{l}34.35 \pm 2.69 \\
34.31 \pm 2.39\end{array}$ & $\begin{array}{l}2.764^{*} \\
-0.153\end{array}$ & 3.008 \\
\hline
\end{tabular}

$\mathrm{t}$ values are pre and post t-test.

F values are between group ANCOVA results. ${ }^{*} p<0.001,{ }^{* *} p<0.01,{ }^{* * *} p<0.001$.

ACE, angiotensin converting enzyme; GFST, $\gamma$-aminobutyric acid-enriched fermented sea tangle; CON, placebo; BDNF, brain derived neurotrophic factor; IL, interleukin; TNF-a, tumor necrosis factor a; HGH, human growth hormone; IGF, insulin-like growth factor; AST, aspartate aminotransferase; ALT, alanine aminotransferase; CK, creatine kinase; TG, triglyceride; LDL, low-density lipoprotein; HDL, high-density lipoprotein. 